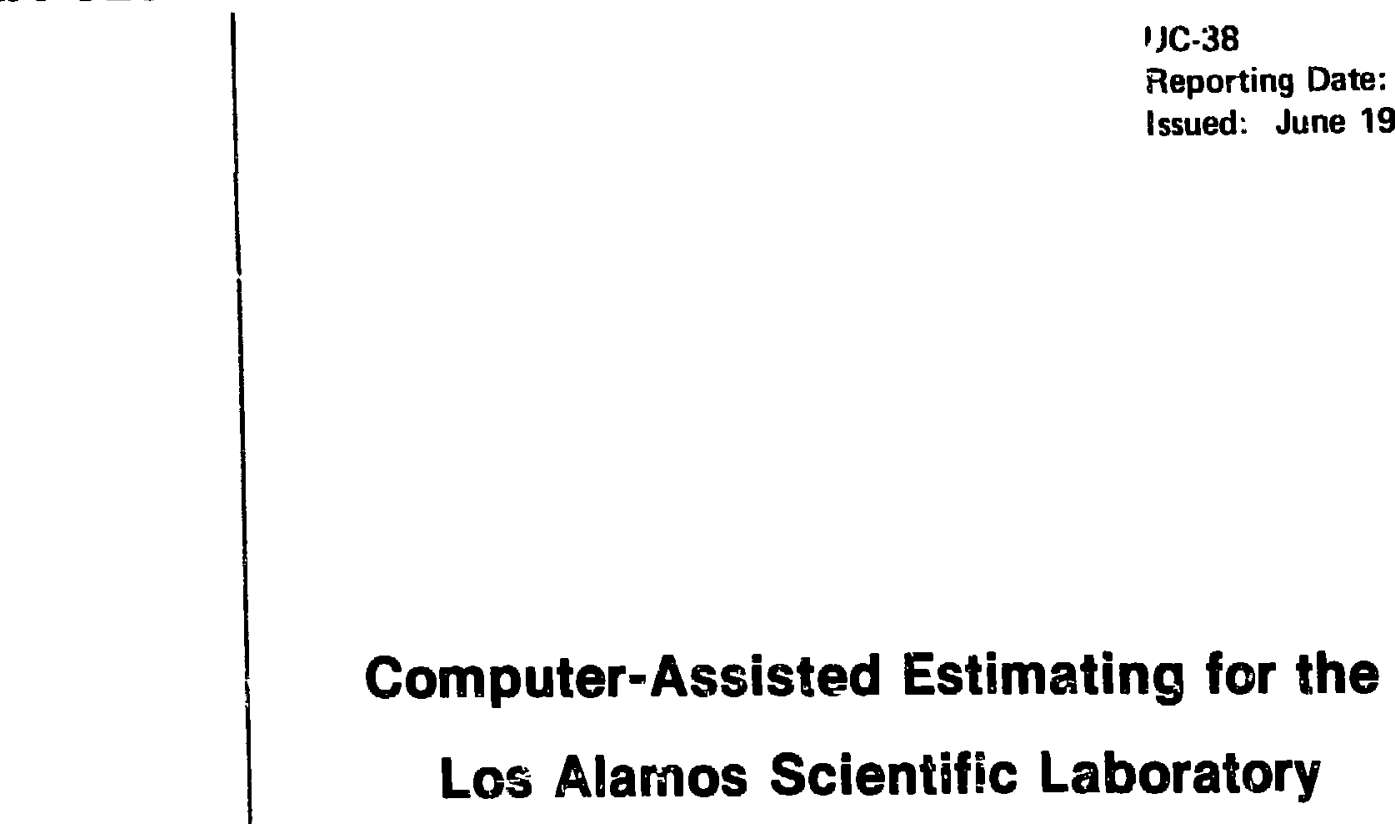

by

James E. Spooner 
Printed in the United States of America. Available from National Technical Ir.formation Service

U.S. Department of Commerce

5285 Port Royal Road

Springfield, VA 22161

Price: Printed Copy \$3.50 Microfiche $\$ 2.25$

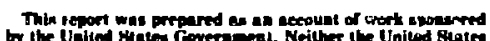

by the Uplied thatew foveraneal. Neiller the Unitod stated

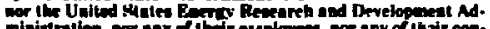

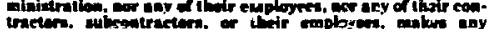

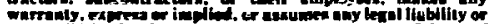

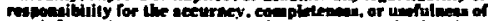

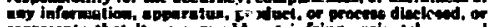

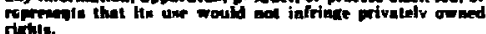




\section{CONTENTS}

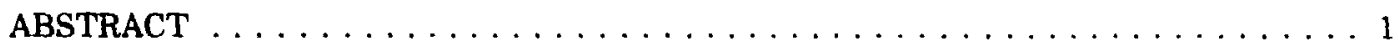

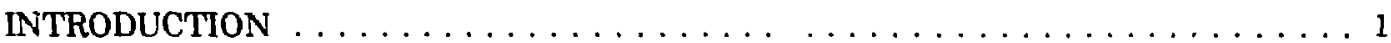

PRESENT COST ESTIMATING AT LASL $\ldots \ldots \ldots \ldots \ldots \ldots \ldots \ldots \ldots \ldots$

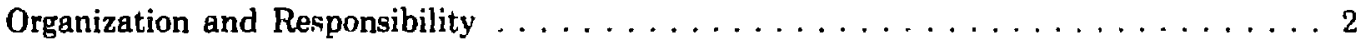

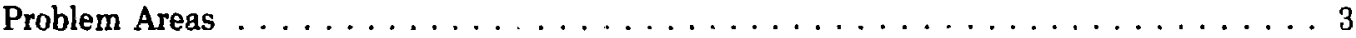

COMMERCIALIYY AVAILABLE CAE SYSTEMS $\ldots \ldots \ldots \ldots \ldots \ldots \ldots \ldots$

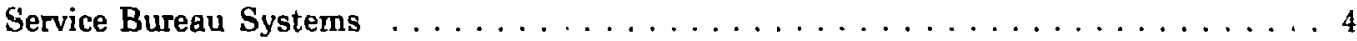

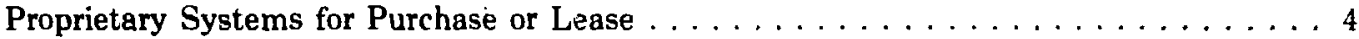

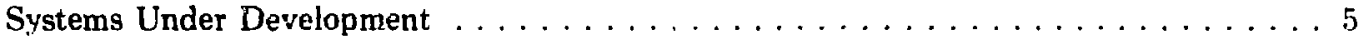

CAE DESIGN REQUIREMENTS FOR LASL $\ldots \ldots \ldots \ldots \ldots \ldots \ldots \ldots$

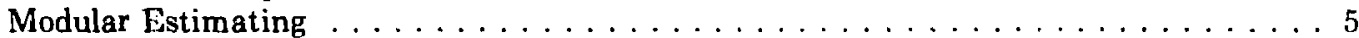

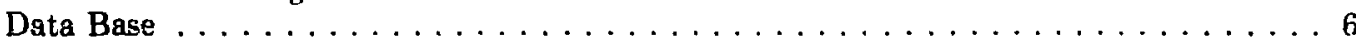

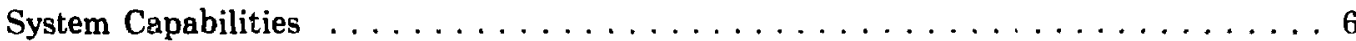

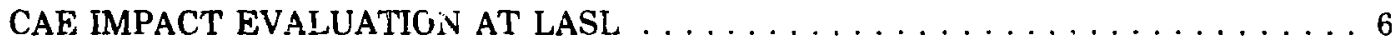

Changes in Estimating Procedures $\ldots \ldots \ldots \ldots \ldots \ldots \ldots \ldots \ldots \ldots$

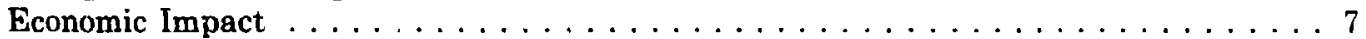

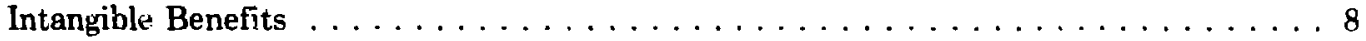

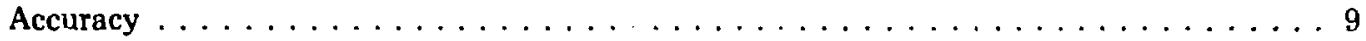

CONCLUSIONS AND RECOMMENDATTONS $\ldots \ldots \ldots \ldots \ldots \ldots$

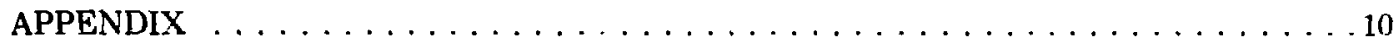




\title{
COMPUTER-ASSISTED ESTIMATING FOR THE LOS ALAMOS SCIENTIFIC LABORATORY
}

\author{
by
}

James E. Spooner

\begin{abstract}
An analysis is made of the cost estimating system currently in use at the Los Alamos Scientific Laboratory (LASL) and the benefits of computer assistance are evaluated. A computer-assisted estimating system (CAE) is proposed for LASL.

CAE can decrease turnaround and provide more flexible response to management requests for cost information and analyses. It can enhance value optimization at the design stage, improve cost control and changeorder justification, and widen the use of cost information in the design process.

CAE costs are not well defined at this time although they appear to break even with present operations. It is recommended that a CAE system description be submitted for contractor consideration and bid shile LASL system development continues concurrently.
\end{abstract}

\section{INTRODUCTION}

Effective use of resources is a dominant objective of management. Money is a proxy that measures resource use; hence budget reliability determines an organization's effectiveness. To satisfy this objective, cost estimating provides information for commitment and control of resource use.

To make Los Alamos Scientific Laboratory (LASL) capital budgets more reliable, the Cost Engineering Group (ENG-8) is attempting to improve cost estimating by improving manual estimating and administrative techniques and by introducing a comprehensive computer-assistad estimating system (CAE). This report discusses the investigations into $\mathrm{CAE}$.

The computer offers certain advantages ovemanual operations in cost estimation: high-speed processing. ertor-free computation, file creation and ruaintenance, and high volume sorting. Table I further elaboratez the operationa: benefits of CAE. Anticipation of these benefits for LASL prompted the current investigation.

Estimates are a function of project development. A typical estimate sequence for a LASL construction project corresponds to the four construction stages: preconceptual, conceptual, Title I, and Title Il.

During the preconceptual stage, the need for a physical plant is established and a feasibility study is made. As the cost estimate required at this time does not require high precision, rough estimating techiniques are acceptable. Square-foot and cubicfoot costs per building are common. Dollars per output unit, such as per patient in a hospital or per thousand gailons per day throughput in a refinery, is acceptable at this time. Few $\mathrm{i}^{\mathrm{s}}$ any design concepts have been developed for this phase.

During the conceptual stage, engineering and other planning are authorized to determine the technological structure of the project. At LASL the estimate produced at this time is used for appropriation requests; therefore, the amount of work involved in a conceptual design report can be quite extensive. Costing techniques can vary from the most approximate to full detail depending on available information.

During the Title I stage, a base line is developed for control during design. The design concept and criterie in the base line encompass the entire scope 


\section{TABLE I}

\section{CAE OPERATIONAL BENEFITS}

Benefit

Reduced errors in processing

Reduced turnaround time

Display capability

\author{
Standardized \\ estimating \\ procedures
}

Incresaed output of estimates

Rapid report production
Extension, summation, and other errors in arithmetic operation are virtually eliminated because no further handling of information is required after processing begins.

Explanation

Time-consuming or repetitive duties, such as catalog look-up, multiplication, and sorted reports, are produced at high speeds with accurate results.

Stored data from previous jobs is resdily available for comparison to current estimates.

Communication between estimator, supervisory personrel, and management is more efficient because piocedures and nomenclature are standardized; consistency at all ievels is assured.

A significant reduction of pencil-and-paper work increases output and reduces takeoff time.

Reports are produced quickly, eliminating the delays associated with manual production. Manual sorting and compiling of takeoff items are eliminated. Rapid report generation provides timely access to previously unavailable reports which, by providing more information, enhance the likelihcod of making intelligent decisions.

Information is processed after takeoff with no additional clerical handling.

expense

of the project so that the cost impact of later changes can be accurately asseosed.

During the Title II stage, design specisications and drawings reach completion. The cost estimate serves Es an independent check of the Title I control process and the constructor's bid to follow the Title II stage. During construction it may also be used to es ablish the value of the construction.

\section{FRgSENT COST ESTIMATING AT LASL}

Capital cost estimating is done in several LASL organizations. The Engineering Department provicles capital cost estimates for facility construction und modification; operating departments provida estimates for equipment acquisition. Although LASL facilities may house unusual equip- inent, the facilities themselves normally can be built with standard construction techniques. However, the unusual does hanpen more often than is common with other engineering organizations, thus requiring additional effort at the conceptual level.

\section{Organization and Responsibility}

Within the Engineering Department several cost estimating centers exist. Primary responsibility resides in the Cost Engineering Group (ENG-8). Other groups exist as part of Facilities Design (ENG-2), the Zia Company, and TA-55 Construction (ENG-14); in most cases ENG-8 has final approval.

The engineering studies group within ENG-2 makes detailed comparisons of alternative designs 
for feasibility. Estimates can vary in detail from moderate to extensive even though they are primarily for feasibility evaluation.

The Zia Company is an independent contractor that sumplies maintenance and construction services to LASL on a cost-plus-fixed-fee basis. It estimates the cost of work and establishes \& bill-of-material. On the whole its estimates are quite detailed. Zia provides other types of estimates in less detail; it also does estimating for ENG-8.

ENG-14 acts as project manager for construction of single large projects at the LASL site. It monitors contractor expenses, validates progress payments, estimates change orders, and forecasts project budgets on a quarterly basis.

ENG-8 provides cost engineering over the whole range of estimates; however, it primarily provides cost advice for the preconceptual ihrough Title I stages. It also reviews Title II estimates prepared by architect-engineer (AE) design consultants. ENG-8 estimates range from minimal to considerable detail evelu for conceptual work.

\section{Problem Areas}

The present use of the conceptual cost estimate for appropriation can lead to embarrassing results for LASL and the US Energy Research and Development Administration (ERDA). In part, this problem stems from limitations of present estimating systems, which provide estimates that lack consistency as design proceeds, provide minimal com. patibility between the estimate for design purposes and the estimate for construction, and support only the most superficial form of value engineering.

Technically a gap occurs between the first estimate and the following two or three produced during project development. An early estimate may be based on square-foot costs of a particular type of construction. Later estimates will be based on more complete data and unit cost information. The transition between estimates may not accurately reflect the real changes because they are not estimates of the same thing: the first estimate is based on an average project with vide confidence limits, whereas the later estimate is based on averages for components. Because of the change in basis it is not possible to follow, with any confidence, the trend of cost as design proceeds. Decisions based on unreliable data often produce undesirable results.

The basic building blocks for a project differ for designer and builder. A designer will think of a partition as a functional unit for separating spaces that has properties such as weight, sound transmission, and color. To the builder, however, the partition represents several different tasks, such as erecting studs, iastalling electrical hardware, applying drywall, and painting. Most commercial estimating systems available concentrate on the construction phase and fail to offer adequate definition of the design phase. It is therefore difficult to reconcile differences between estimates prepared by designer and builder.

Quite often decisions made during the design phase will affect the cost of the project more radically than any control exercised during construction. Effective decision making during design depends on the adequacy of the estimating system. It is often impossible to reflect cost consequences produced by manual techniques as differences found may be more apparent than real. Thus cost control is inadequately supported by present techniques. At present no reliable munitor or control capability exists at LASI.

Ir compatibility between LASL and Zia estimating procedures is another situation that sometimes produces difficulties. As discussed earlier, the functions of LASL and Zia estimating departments are not identical. Simply stated, LASL forecasts costs for financial planning, whereas $\mathrm{Zia}$ provides a cost and bill-of-material for control purposes. Zia might separate the functions of cost estimating and material ordering if it were in competition with other contractors. However, its relationship to LASL is such that most Ziaestimated projects are funded. Thus it is economical for Zia to combine the two functions, and this is the source of most difficulties.

Especially critical are adequate estimates of the mechanical and electrical systems found in the experiments themselves. Although cost estimation of the process part of a project has traditionally been done by the group involved, ENG-8 has recently taken a more active role. Cost of the process equipment quite often is several times the cost of the remainder of the project and thus constitutes a critical part of the recommended budget. ENG-8 expects to expand its effort in this direction with beneficial results.

\section{COMMERCIALLY AVAILABLE CAE SYSTEMS}

An intensive survey was made of CAE systems in development as well as in use. A short description follows for each system of interest to LASL. Company addresses and further comments for all systems surveyed are given in the Appendix. 
Evaluation of several CAE systems is presently in propress; complerion is expected in early November 1976. Tests are being conducted on a stand-alone system using a minicomputer, the Varian approach to cost estimating, and on an interactive sysiem available through a computer service bureat, the Orr method.

There are very few firms directly involved in CAE. Three of the firms surveyed were no longer in business. Their high mortality rate should be considered brfore approaching a supplier for a data base or CAE system.

A brief description follows for selected firms to give essential system characteristics, such as support of estimate production throughout the project, data base characteristics, and method of communication with the system.

\section{Service Bureau Systems}

Cost Systems Engineers has created the Orr System, one of the first CAE systems available on a commercial basis, providing a wide range of estimating capabilities. Estimates can be initiated at the earliest stages and adjusted as design proceeds. Thus an estimate can be initiated on the basis of a parameter, such as pupils in a school, and carried through to the bidding stage where a detailed takeoff can be made from complezed plans and specifications.

Data is selected from a handbook and manually coded onto a standard form. The encoded information is then entered via a terminal with the help of a prompter prog:am. The data base consists of about 35000 items.

Wood and Tower, a cost consultant firm, has developed a simple system defined at the conceptual and detailed levels. Conceptual design is estimated by building type and cost per area. Intermediate estimates between conceptual and final design are produced as detailed estimates where reliance is placed on the expertise of the estimator to provide information that is not available in the existing design.

Data is coded manually on standard forms from a handbook of about 2700 items Encoded data can be keypunched and processed on a batch basis or entered via terminal to a service bureau computer.

\section{Proprietary Systems for Purchase or Lease}

\section{Advanced Management Information Systems} (AMIS) is an independent construction- management organization that offers services to owners. It has been working on computer-aided management techniques for more than $7 \mathrm{yr}$.

At its more sophisticated level the AMIS system uses a resident model of the project under consideration. The model is predetermined at a detailed level according to type of project. Subsequent changes to the project can ive directly compared to previous detailed information. Thus the effect of decisions is immediately reflected in estimated project costs. It is possible, therefore, to build a detailed cost breakdown of a project with little information and then gradually update the estimate as more informarion becomes available.

The AMIS data base has approsimately 7000 items; each item includes typical factors for construction crew and productivity in time units of production from which unit manhours can be calculated for subsequent use in estimating. Local union practices and productivity can be taken into account. The original mode' definition, although time consuming, will be altered infrequently thereafter.

Because many of the model's default options are based on approximate engineering design routines, the resulting estimates are more reliable than those made from experience alone. This value engineering capability would be expensive and tinue consuming in a manual system. Moreover, the detailed design can be checked against the resident pool of data.

Computer input can be entered via terminal in either batch or interactive mode. In interactive mode, prompts lead the user through the proper sequence of decisions to supply sufficient information. A graphics input capability is prese:.tly being developed.

Smith-Hinchman and Grylls (SHG) is a large $\mathrm{AE}$ firm concerned with a broed scope of building construction. The SHG system uses a tree structure to organize project information into larger groupings or assemblies which correspond to project management and design. This structure, constructed from the bottom up, does not reside in the computer at initial project definition. However, information created from a previous project may serve as a checklist for creating the structure of subsequent projects.

System inpuit is measured manually and priced from existing catalogs or quotations. An empty data base structure exists. Data is manually coded onto stanciard forms and is entered on punched cards at the present time; however, an interactive terminal system is being developed. Adjustment factors lưr 
productivity or complexity car be entered with an incividual item or at accumulated levels.

Project Control Associates offers interdisciplinary support to owners and AEs during project design and construction. A wholly owned subsidiary of C. F. Murphy Associates, it has been involved in many large and complex projects. The staff has many years of experience in the management of construction projects, both for owners and builders.

This is essentially a detail-estimating system with a facility for establishing a library of coinmonly used assemblies. These assemblies can be quite complex, yet any one can be called up by specifying a single name. In addition, the system can produce a bill-ofmaterial for purchasing and provide calculation soutines for detailed design of a few systems.

The program is divided into areas of general construction, mechanical, and electrical systems. Manual input uses a catalog and extensive data base; the coding system is based on the Uniform Cons'ruction Index (UCI) at the detailed level. At the assembly level, empirical codes have been established for each specialized area. Comments may be included with the input for documentation purposes.

The Management Computer Controls (MCC) system is not commercially available. It was developed in the early sixties by a construction company. MCC is now an independent organization that offers cost estimating and scheduling services for owners ar:d contractors.

The system operates only at a detailed level, but employs a unique method of assemblies for accessing the data base. A functional or construction system can be defined by an assembly of components. Thus a matrix provides the menu for a system description: a generic description of components constitutes the top row, and specific examples that exist in the data base appear in the columns under the generic heading. These generic assemblies cover the areas of civil construction and are being expanded further in the mechanical and electrical areas.

Data is manually coded on standard forms and then keypunched for batch processing. The system supports an extensive data base.

\section{Systems Under Development}

The Varian Corporation is developing a Construction Data System (CDS) in cooperation with potential user organizations such as design and construction companies. Thus the system is being shaped by the needs of the user. Both detailed and conceptual levels are under development.

CDS runs on a minicomputer with a patented console for data generation and quantity takeoff. The console has a matrix of keys for identifying project components and a numeric pad and probes for measuring them. Masks in abbreviated English overlay the matrix of keys to define generic assemblies. The user depresses a key to activate the proper processing program and to display questions on the console. His responses will provide enough information to identify and quantify an element of the resident data base. Only the structure for the data base is provided.

The British Consortium for Method Building requested the Royal College of Art to develop a Cost Advice System specifically for providing cost information during the early and middle stages of design.

A resident isodel of a similar project supplies hypothetical quantities where information does not exist; gradually this model is replaced with actual data. The basically interactive system accommodates the occasional user. However, there does not appear to be an integrated data base.

Construction Engineering Research Laboratory is developing an estimating system for the US Army Corps of Engineers. It has made an extensive investigation to determine what system characteristics are desirable. Preliminary information indicates that the system will be structured for use throughout the design aind construction process. The conceptual part of the system is being field tested at the present time, but full development and implementation appear to be several years away.

\section{CAE DESIGN REQUIREMENTS FOR LASL}

The foregoing discussion has attempted to establish the existing characteristics and LASL constraints on a CAE system. The available CAE systems surveyed have useful features, but no one system satisfies all LASL requirements. Either LASL must compromise on the best available system or develop its own. This section describes the features that ENG-8 recommends for a LASL system.

\section{Modular Estimating}

One requirement for a LASL estimating system is the ability to call upon a previously defined project model at the conceptual or appropriatios: stage for 
subsequent tracking and justification of changes. Ideally, the original model contains as much detail as the Title II estimate, however it is based on little information and many assumptions. As information accumulates during project development, initial assumptions are replaced. This approach requires the capability to define, modify, and call system assemblies 00 that minimal input can produce a complete estimate. Thus the project model becomes an assembly of assemblies.

We call this approach modular estimating; the procese fits existing units or modules together to produce a nonoverlapping yet complete image of a project. The project is analyzed into functional systems that correspond to modules in the estimating system library. A module is defined broadly enough to provide full physical support for a function, yet narrowly enough to provide good correlation between the cost of the system and a quantity measure. The content of the module is defined at two levels: design and detailed construction. Although the information is organized to contorm to design, computer sorting can reorganize the detailec' level into a form suitable for construction. Internally, the design level is defined in terms of representative quantities of the detailed components. The module can be accessed at either level, but the design level will produce a detailed takeoff thro ugh default assumptions. Thus, compatibility with the needs of the usPr is achieved and consistency among estimates is produced. Defects of other systems, if not entirely removed, can be significantly diminished.

\section{Data Base}

A cost and productivity data base specific to LASL operations is necessary to increase the accuracy of near-term projects and allow direct interface with $\mathrm{Zia}$ operations. This can be best accomplished by incorporating the Zia duta base into the data base for the proposed system. The high mortality of consulting firms in cost engineering makes it necessary to structure the data base so that someone other than the designing firm can update it. To this effect, manhours is a better measure of labor productivity than dollars.

\section{System Capabilities}

Compatibility with Planning. Output from the estimating system must be compatible with later project planning and scheduling. At the detailed level, estimating system output should be in a format suitable for input to a planning and scheduling system. Output should be in days or weeks of duration rather than manhours; there must be a craft breakdown; and tasks should be easily definable in terms of duration and required craft resources, as well as money. This is consistent with the previously mentioned requirement for time- rather than dollarbased productivity.

Terminal Access. Because construction and estimating expertise of users varies, a terminaloriented conversatiunal system can minimize personnel training and accommodate the occasional user. To serve the many users who need cost advice, 8 to 12 terminal locations are needed.

Manual Operation. Whether supported by the central computer facilities at LASL or by minicomputer, the system should be capable of manual operation in the event of computer difficulties.

Consistency in Level of Detail. A cost accounting code that assures consistency between LASL and Zia can solve most of the reconciliation problems between the two organizations. However, the code should provide the framework for bill-of-material generation.

Cost Modeling. The survey of existing systems found little reason to expect improvement in cost estimation of the experimental equipment used by many LASL projects. The proposed CAE system for LASL should provide the capability for construction of a project model to permit parametric studies.

\section{CAE IMPACT EVALUATION AT LASL}

ENG-8 performs different types of estimating:

- Originate an estimate for a new project;

$$
\text { - Update an existing estimate due to passage of }
$$
time;

- Rework an existing estimate to incorporate major revisions;

- Compare a present to a previous estimate tu monitor and justify changes; and

- Eveluate a contractor's estimate and reconcile differences with LASL's estimate. 
In this section CAE impact will be evaluated in terms of changes to LASL estimating procedures, economic considerations, intangible benefits, and accuracy of cost estimating.

\section{Chenges in Estimating Procedures}

Creating a new estimate requires the full scope of estimating procedures. The time involved is a function of project information available. Comparisons of various tachniques are shown in Tables II and III. The manual technique is taken as the base line condition. Electronic takeoff uses electronic measuring devices for quentity determination; all other operations are manual. Full CAE assumes electronic probes that transfer data directly to computer memory and an interactive program that prompts the user to make decisions.

Tables II and III compare the three techniques. The times used are based on a consensus of opinion within ENG-8 and are intended only as an ipproximation of the values involved. However, the ratios produced are relatively insensitive to the assumptions made and should be reliable. Thus, use of an electronic oid reduces estimated time to about $90 \%$ of manual, and full CAE techniques reduce it to $75 \%$ of manual time. Where assemblies are ust $d$ for $25 \%$ of the catalog items with a concentration ratio of 3 to 1, CAE may reduce the time to 60 to $65 \%$ of manual time. Values in this order of magnitude are being claimed by proponents of existing CAE systems, and on the basis of this analysis they seem justified.
Because creation of new estimates is the primary function of estimating, the remaining operations will be discussed in a more cursory fashion.

Updating an existing estimate attests to $\mathrm{CAE}$ effectiveness; the time involved amounts to retrieving the old estimate from computer-compatible storage, re-entering it into the system, and requesting pricing according to current data. When snly catalog items ere involved, the time may be less than $10 \%$ of manual time.

Reworking an existing estimate for major revisions is a nonstandard situation difficult to analyze. It can occur during conceptual design, when several alternatives are being considered; then a complete estimate for each project must be produced for direct comparison. In such a case the original estimate can be changed selectively with ease, coropared to manual techniques. Alternate preparation time may be reduced by $50 \%$, a significant saving. The same time saving applies to revisions that occur as design proceeds.

Reconciliation of estimates prepared from different sources cannot be handled by a CAE system except for $\mathrm{Zia}$ and then only if $\mathrm{Zia}$ and LASL use the same data base. A remedy for this situation is not a computer system but, as discussed earlier, a common code of accounts for costs.

\section{Economic Impact}

The economic consequences of a change in operation can be measured in terms of increase ini profit or

TABLE II TIME COMPAKISON OF ESTIMATING PROCEDURES
FOR A SINGLE CATALOG ITEM

\begin{tabular}{|c|c|c|c|}
\hline & Manual (min) & $\begin{array}{c}\text { Electronic } \\
\text { Takecff (min) }\end{array}$ & $\begin{array}{c}\text { Full } \\
\text { CAE (min) }\end{array}$ \\
\hline Identify/cutalog loak-up & 1.5 & 1.5 & 0.7 \\
\hline Name/data transfer & 1.0 & 1.0 & $\ldots$ \\
\hline Measure & 4.0 & 2.5 & 2.5 \\
\hline Record measurement & 1.5 & 0.7 & $\ldots$ \\
\hline Extend & 2.0 & 1.0 & -.. \\
\hline Fixed time & 7.0 & 7.0 & 7.0 \\
\hline Total & 17.0 & 13.7 & 10.2 \\
\hline
\end{tabular}




\section{TABLE III}

\section{TIME COMPARISON OF ESTIMATING PROCEDURES FOR 100 ITEM ESTIMATE}

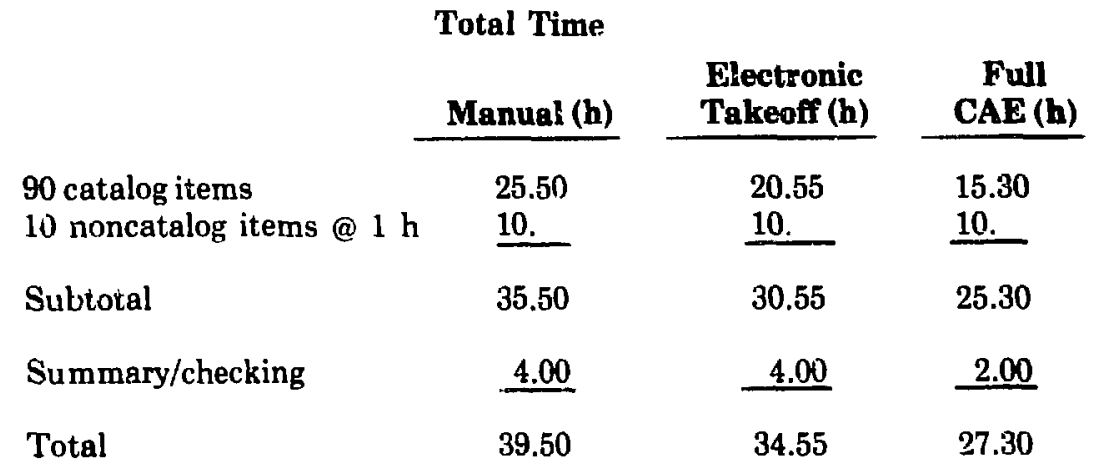

Ratio to Manual Time

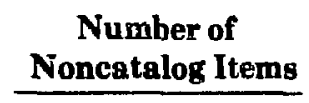

10

20

30
1.0

1.0

1.0

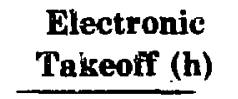

0.87

0.91

0.93
Full

CAE (h)

0.69

0.76

0.82 decrease in expense. Profit making obviously is inappropriate for LASL, hence cost reduction is where our interest lies.

The expense of cost estimating can be reduced in two areas. First is to eliminate practically all overtime. Taking CAE time as equivalent to $75 \%$ of time for manual operations and assuming overtime to be less than $4 \mathrm{~h}$ per day. CAE can eliminate most overtime hours. Most of this overtime is not formally sanctioned and does not produce a cash expense. However, CAE can ameliorate an irregular situation in the use of personnel.

Second is to increase productivity. The total workload in ENG-8 is such that some of its estimating work, amounting to about 6000 manhours in FY75, has been transferred to the Zia estimating department. The present three estimators in ENG-8 using a CAE system could turn out work equivalent to four estimators working manually using the ratio of 0.75 for the effect of CAE operation. This is equivalent to $2000 \mathrm{~h}$ of estimating that would not have to be shipped to Zia, or $\$ 20000$. The offsetting cost of a CAE system is not known accurately at this time, but its expense would probably be no more than the cash savings. Intangible benefits thus gained would be at nominal cost.

\section{Intangible Benefits}

A CAE system promises beneficial impact in areas that cannot be evaluated by means of cost.

Response to Changes. Error correction, deliberate changes, or value analyses of a project can be quickly incorporated and effects on project cost determined almost immediately.

Consistency. Development and use of a CAE system lead to standardization of procedures and data base. At the present time, LASL and Zia use different data bases and cost breakdowns. Even within the LASL organization many different source documents are used and unit prices vary; estimators define jobs differently. A standard approach will provide estimators with a basic framework from which they can develop similarly structured results. 
Value Optimization. A great deal of lip service is given to the concept of value optimization under the names "value engineering" and "life cycle costs." Quite often the ineffectiveness of the technique is disguised by the crudeness of the cost system. Manual techniques produce rough models whose differences should be recognized only if they are significant. Computer models can be much more precise and useful for detailed decision making. Although the initial eftort to define the model takes more time than manual investigation, the effort is expended only once rather than every time. The computer model can be improved continually for greater sensitirity to design paramelers and hence better decisions. Improvement to a manual model is usually discouraged because of time constraints.

Decisions made during design will affect the cost of the project to a greater extent than later decisions. Therefore, the optimization capability of the CAE system should be attractive and useful to a wide range of project personnel, especially those in design.

Conceptual Design. Projects and parts of prnjects that have similar end usage will have similar design and similar cost structure. Because of this property, it is possible tr construct a useful hypothetical model for establishing cost at the conceptual level. Where the model is already resident the procedure is accelerated.

Cost Control. Once the budget has been set, the designer is as concerned with cost control as with optimization. The potential precision of the mathematical models will provide the besis for greater confidence in the tradeoffe that may become necessary.

Justification for Changes. Often overlooked in CAE discussions is the support that it provides for management in correlating cost changes with design decisions. It can be a frustrating experience to justify an increase in estimated project cost and then have to reconstruct manually all the changes that have accumulated. With CAE this process can be visualized by simply calling forth a summary report of the changes and effects on project cost. Change impact thus becomes highly visible to management.

Checking. Validity of the estimate as checked by the production of system parameter costs and physical ratios can be created much more effectively by computer than by hand.

\section{Accuracy}

CAE can eliminate errors due to arithmetic manipulation. Its use, however, will not significantly increase accuracy and precision of estimates as long as one relies on translation of manual techniques to the conputer. However, I do believe that improvements will occur for the following reasons:

- Standardizativn of procedure and scope definition will decrease errors due to oversight.

- Availability of cost models dependent on more design information will exert pressure to produce more design data earlier. This can be accomplished most readily by the development of computerized approximate design routines.

- As more conplex models are developed they will provide a more faithful image of the project and greater sensitivity to changes for more intelligent cost control.

\section{CONCLUSIONS AND RECOMHENDATIONS}

A CAE system can be an extremely useful tool for improving much construction estimation at LASL, but it cannot replace expertise, especially for evaluating specialized experimental systems.

- CAE systems with attractive features are available, but no one system provides all the features sought for LASL

- A CAE system tailored to LASL needs can increase the number of users capable of accessing cost information and encourage cost optimization during the design phase.

- It is not feasible to provide Zia with a CAE system that immediately allows it to produce a billof-material for purchase and control of materials, but it is feasible to provide an assembly definition capability.

- Zia will be able to use the processing and report writing capability of the CAE system. Its data base can be incorporated into the system. 
- LASL and Zia should put into use a code of accounts that defines design components of a project rather than construction elements.

- A CAE system design should make it easy for even an occasional user to use the system starting at scope definition and continuing through construction planning.

The foregoing conclusions suggest that a CAF system for LASL is desirable but no entirely ruitable one is available. Assuming that management agrees with this assessment and authorizes further work, there still remains the approach to take for system development.

Alternatives to be considered are whether LASL should develop its own systen or hire a contractor. In either case it will take 1 to 2 yr for a welldeveloped system, although portions will be usa' ' $e$ before then.

For LASL to develop its own system might seem attractive because no incremental cost is invoived, but these savings may be more apparent than real.
Hiring a consultant knowledgeable in the art also has merit as his experience will be reflected in the final design. In respect to such considerations, I recommend the following approach.

- Develop a CAE system description to provide a basis for proposal by consultants.

- Continue LASL investigations into development of a CAE system.

- Acquire an available CAE for use on a tem. porary basis until the LASL system is operational.

During the period of development a temporary CAE system can provide LASL with many of the capabilities its own system will have. It can also provide experience leading to improvements in LASL's system. LASL should continue its own development during the design period to locate problems that may remain latent until more critical developments are under way.

\section{APPENDIX}

\section{COST-ESTIMATING SERVICES}

The firms listed here market CAE systems, data bases, and electronic aids related to building construction; they are categorized by type of service offered. The list is probably as good as any that exists in the commercial area at the time of writing (August 1975), but it certainly is not exhaustive.

CAE systems not discussed in the body of the report are discussed here immediately following the name of the firm that markets them.

\section{COMPUTER-ASSISTED ESTIMATING SYSTEMS}

\author{
AMIS Consulting Services \\ 50 East 42nd Street \\ New York, NY 10017 \\ Smith-Hinchman \& Grylls Associates \\ 455 West Fourth Street \\ Detroit, MI 48226
}

Wood \& Tower

Research Park, Box 28

Princeton, NJ 08540

Esti-Pak, Inc. 1925 South West Temple 'Salt Lake City, UT' 84115

An imposing data base in both mechanical and electrical systems containing approximately 400000 itenis. A CAE system is evailable that is dedicated to detailed estimating. Noninteractive.

Estimatic Corporation

2480 West 4th Avenue

Denver, CO 8022?

An impressive system capable of producing not only a detailed estimate, but also a detailed bill-ofmaterial for purchasing. Assemblies are used extensively to minimize takeoff definition. Noninteractive. Electrical systems only. Data base contains 
about 60000 assemblies and hundreds of thousands of detailed items.

\section{Applicon}

Evergreer. Executive Suites

Route 3, Box 10-A

Evergreen, $\mathrm{CO} 80439$

Primatily a computer-aided drafting system. Applicon has created for Herman Blume Consulting Engineers of Dallas, TX, a computer-aided design system that incorporates an estimating routine. Mechanical systems.

Edward G. Scharf \& Son

8555 Connecticut Avenue NW

Washington, DC 20015

Cost consultant offering a iuil srope of services in the building construction area. Uses CAE and maintains own data base.

Construction Data Services Division

Varian Associates

611 Hansen Way

Palo Alto, CA 9430s

Project Control Associates

224 South Michigan Avenue

Chicago, IL 60604

Cost Systems Engineers, Inc.

4907 Ohio Garden Road

Fort Worth, TX 76114

American Appraisal Co.

525 East Michigan Street

Milwaukee, WI 63201

The CAE maintained by American Appraisal is meant for building valuation rather than capital cost estimation.

Instant Data Access Control

425 East 53rd Street

New York, NY 10022

This organization is primarily devoted to data retrieval for architects and as such provides facilities for storage and retrieval of costs; however, capital cost estimating is not strongly supported.

Management Computer Controls

2714 Union Ext.

Memphis, TN 38112
Naval Facilities Enginecring Command

200 Stovall Street

Alexandria, VA 22332

Detailed system using an extensive lata base of about 20000 items covering the 16 categories of the CSI/LICI coding syatem. Noninteractive.

Directorate General of Development

Department of Environment

Lunar House

40 Wellesley Road

Croydon CR9 2EI.

ENGLAND

This Cost of Contractors Operation (COCO) system directs attention to the contractors' plan for high-rise buildings. Capabilities for estimating cost and installation of materials are not well developed yet. Interactive.

Roy?: College of Art

De ,artment of Design Research

$\mathrm{K} \epsilon_{i}$ isington Gore

London SW7 2EU

ENGLAIND

Bowerman Bros.

Providence, RI

System not commercially available at time of inquiry (February 1975).

Department of Architectural Engineering

Pennsylvania State College

University Park, PA 16802

MODCON is intended to be an interactive computer-aided building design system which, on proper command, provides a cost estimate. This capability exists in concept only (Octoher 1975).

Construction Engineering Research Laboratory

P. O. Box 4005

Champaign, IL 61820

ICARUS

8630 Fenton Street

Silver Spring, MD 20910

ICAFUS does not have a system for building construction but it does have a CAE system called COST, which includes many of the concepts discussed for the LASL system. Its area of expertise is in the process industries. 
Construction Infornation Systems

Box 484

Mill Valley, CA 94941

Basically a detailed system thet can define summary levels in a flexible manner. Several different methods are available to spread a contractor cost account to a bid account. The code is written in Assembler Language for the IBM System/360.

Ralph M. Parsons Co.

Pasedena, CA 91124

A cost-estimating system that contains many of the features required for a LASL system. A detailed system with a potential for summarizing at higher levels. Not commercially available at this time.

Oak Ridge Nationa! Laboratory

P. O. Box P

Oak Ridge, TN 37830

Several programs for computer-aided cost estimating have been developed at ORNL. Cost models have been developed for several types of power plants and incorporated into a program called CONCEPT. ECON is presently being developed as a system for detailed estimating and multiple summarization.

Autotrol

5650 North Pecos

Denver, CO 80221

Similar in intent to the Applicon system. Autotrol claims capabilities for bill-of-material generation over the complete range of construction estimating.

A. A. Mathews

41 West Santa Clara Street

Arcadia, CA 91006

This system is designed to satisfy the constructor's reeds and, therefore, is perhaps not flexible or general enough for the designer to use with ease. Written in COBOL. Interfaces with time and resource scheduling systems.

\section{DATA BASE}

National Electrical Contractors Association 7315 Wisconsin Avenue NW

Washington, DC 20014
The Manual of Labu; Units provides standard productivity units for a wide range of electrical construction. Available either as a reference book or computer tape.

National Association of Plumbing

Heating-Cuoling Contractors

1016 20th Street NW

Washington, DC 20036

Labor Calculator II is a rather limited manual for productivity information in plumbing and HVAC.

Trade Service Publications

2720 Beverly Blvd.

Los Angeles, CA 90057

List price informstion for both elecirical and mechanical material items is provided by the Price File Maintenance Service. Discount factors must be obtained by user. Only electrical file is available on computer tape.

\section{ELECTRONIC AIDS}

\section{DAME}

Environmental Systems Construction Co.

4412 South 89th Street

Omaha, NB 68127

The DAME System makes use of a specially designed console for data acquisition and encoding on punched cards. These cards are then computer processed in a conventional manner. Set up at present for mechanical/electrical systems.

Estimation, Inc.

7133 Rutherford Park

Security Industrial Park

Baltimore, MD 21207

This firm produces an electronic-aided quantity takeoff device that can be programmed to do simple calculations and accumulations.

Diversified Electronics

720 East Evelyn Avenue

Sunnyvale, CA 94086

Similar product to that of Estimation, Inc. 